Research Letter

\title{
THz therapy and smoking: facts and hypotheses
}

\author{
Svetlana S. Parshina \\ Saratov State Medical University n.a. V.I. Razumovsky, Saratov, Russia
}

Received 20 August 2013, Accepted 2 October 2013

(C) 2013, Parshina S.S.

(C) 2013, Russian Open Medical Journal

Abstract: There had been studied an antianginal effect and hemodynamic effects of THz electromagnetic waves of molecular NO spectrum $(150.176 \ldots 150.664 \mathrm{GHz})$ in 19 smokers and 18 non-smokers patients with angina. It had been fixed that antianginal, pulse slowing and antihypertensive effects of $\mathrm{THz}$ waves in both groups did not differ.

Keywords: smoking, THz therapy, angina

Cite as Parshina SS. THz therapy and smoking: facts and hypotheses. Russian Open Medical Journal 2013; 2: 0410.

Correspondence to Prof. Svetlana S. Parshina. Address: Saratov State Medical University, 121, Bolshaya Kazachya str., Saratov, 410012, Russia. E-mail: parshinasvetlana@rambler.ru

\section{Introduction}

It is well-known that smoking is an independent and one of the basic risk factors of an ischemic heart disease (IHD) developing. Introduction of innovative methods of an ischemic heart disease treatment into clinical practice involves studying of a sensitivity of patients to the given exposure, depending on a smoking factor, to increase an efficiency of the therapeutic interventions. In connection with this, the study of the THz-therapy effects in smoking and non-smoking cardiac patients is a current medical question.

The use of $\mathrm{THz}$ electromagnetic irradiation (EMI) of a molecular nitrogen oxide (NO) (150.176 ... $150.664 \mathrm{GHz}$ ) (terahertz therapy or THz-therapy-NO) in a clinical cardiology was introduced in 2004 [1]. Today scientists know about antianginal, antihypertensive, rheoprotective, hypocoagulative effects of $\mathrm{THz}$ therapy-NO in patients with angina [2-4], there are data of a high hypertensive effect of $\mathrm{THz}$ waves in male patients (comparing with females) [5].

Nitrogen oxide - a "signal molecule of a cardiovascular system" [6] - takes part in a regulation of vascular tone as an exogenic vasodilator, and slows down thrombocyte aggregation, $\mathrm{NO}$ is also a component of stress-limiting mechanisms $[7,8]$.

There are experimental data of an effect of THz EMI of a molecular NO on nitrites concentration in blood plasma of white rats, which can explain realization of THz-therapy-NO through a modulation of NO cycle activity [9].

As NO takes part in regulation of cardiovascular and other physiological systems (respiratory system, gastrointestinal tract, etc.) $[7,8]$, its condition can differ significantly in patients depending on a severity of a state, comorbidities and environmental factors of chronic intoxication - smoking, as well. In connection with this there is a reason to study a sensitivity of patients with angina to $\mathrm{THz}$ radiation depending on risk factors, evidence of a heart failure, etc., as it is important to go by an individual attention in the usage of THz-therapy-NO and to take into account all components which can decrease the efficiency of the treatment.

The study aimed the research of antianginal effect and hemodynamics features of the THz-therapy-NO usage in smokers and non-smokers with angina.

\section{Material and Methods}

There had been 37 patients with angina examined (unstable and stable effort angina of II-III f.c.), who got an EMI of THz-NO treatment on the background of a general drug therapy (aspirin, $\beta$ adrenoblocker, nitrates and etc.). 18 non-smoking patients were in the group I, 19 smokers - in the group II. The groups were comparable at diagnosis, age, myocardial infarction episode, arterial hypertension, blood circulation and rhythm defects and drug therapy.

All the patients in the group of smokers were men, in the group of non-smokers there were $33.3 \%$ of men and $66.7 \%$ of women. As we had revealed earlier that antianginal and pulse slowing effects of THz-therapy-NO do not depend on a sex in the patients with angina [5], and parameters of arterial pressure differ only for systolic arterial pressure (more evident in men), so, we had decided to pay no regard to the difference in sexes in the given groups.

An exposure of EMI of THz-NO had been performed with the use of a portable generator. An intermittent irradiation time-mode «3/15» had been used. The transmission delivered $500 \mu \mathrm{W}$, irradiator had been located $4 \mathrm{~cm}$ above the metasternum, the power density was $17.4 \mu \mathrm{W} / \mathrm{cm}^{2}$. Irradiation treatment course -10 sets.

There had been estimated: antianginal effect of treatment, dynamics of a heart rate (HR), parameters of systolic and diastolic arterial pressure (AD). An antianginal treatment effect was estimated in points according to a relative change of the numbers 
Cardiology

of angina episodes per day and daily nitroglycerin maintenance. Clinical efficiency had been considered high (excellent) at a total elimination of angina episodes ( 3 points), well - at a decrease of throes and daily nitroglycerin maintenance to $75 \%$ and more from the initial level ( 2 points). At the decrease of anginal pain episodes and daily nitroglycerin maintenance in the range of $50-75 \%$ the effect was estimated as moderate (1 point). The absence of an antianginal effect was determined as 0 points, recrudescence -1 point.

\section{Results}

To evaluate homogeneity of a clinical state of the both groups there had been performed a comparative research of the initial frequency of angina episodes and daily nitroglycerin maintenance, values of HR, systolic and diastolic blood pressure (BP) (Table 1). These parameters of the smokers and non-smokers did not differ $(p>0.05)$. Besides, the groups were comparable at an origin of a drug antianginal, pulse slowing and hypotensive therapy $(p>0.05)$.

At the dismissal from hospital the numbers of angina episodes in both groups there had been fixed a significant decrease of angina episodes $(p<0.05)$ (Table 1$)$. Deterioration in the condition had not been revealed in the patients. Angina episodes after the THz-therapy-NO course in smoking and non-smoking patients did not differ $(p>0.05)$.

At the comparison of antianginal effect of EMI of THz-NO (in points) there had not been revealed a significant difference in the groups of smoking and non-smoking patients: parameters were $2.62 \pm 0.18$ points and $2.50 \pm 0.27$ points correspondingly $(p>0.05)$. Stabilization of the patients' state using the THz-therapy was at the same periods: in the group of smokers up to $4.38 \pm 0.46$ session, in the group of non-smokers - to $5.42 \pm 1.04$ session ( $p>0.05)$. The given data display that smoking influences the sensitivity of patients to antianginal effect of $\mathrm{THz}$ waves.

At the same time we got the data which made us suspect that there were differences between a sensitivity of smoking and nonsmoking patients to the $\mathrm{THz}$ waves exposure. So, during the analyzing of a daily nitroglycerin maintenance (Table 1 ) in the group of non-smokers, there had been revealed a clear, statistically valid, decrease of a daily nitroglycerin maintenance $(p<0.05)$ up to practically total refuse, which is logical in accordance with a positive dynamics of parameter "throes episodes per day". In the group of smokers there were other results: despite of a decrease of throes episodes $(p<0.05)$, statistically valid decrease of a daily nitroglycerin maintenance, there was an evident tendency to a decrease of this parameter ( $p>0.05)$.

An estimation of a HR dynamics displayed that in smokers, as in non-smokers, at the dismissal from hospital the was a statistically valid decrease of this parameter $(p<0.05)$, and $H R$ parameters had been comparable at the end of the treatment $(p>0,05)$.

The use of EMI of THz-NO stimulated a decrease of systolic and diastolic arterial pressure parameters, the value of which were lower (statistically valid) than at the moment of hospitalization as in smoking as in non-smoking patients with angina $(p<0.05)$ (Table 1). An antihypertensive effect of $\mathrm{THz}$ waves was the same in the both groups: after the course of THz-therapy-NO systolic and diastolic arterial pressure did not differ in smoking and in nonsmoking patients $(p>0.05)$.
Table 1. An antianginal effect and hemodynamics parameters in smoking and non-smoking patients with angina at the use of THz-therapy-NO (M $\pm m)$

\begin{tabular}{|c|c|c|c|}
\hline \multirow[t]{2}{*}{ Parameters } & \multirow{2}{*}{$\begin{array}{l}\text { Follow-up } \\
\text { period }\end{array}$} & \multicolumn{2}{|c|}{ Groups of persons with angina } \\
\hline & & $\begin{array}{c}\text { Smokers } \\
(n=18)\end{array}$ & $\begin{array}{c}\text { Non-smokers } \\
(n=19)\end{array}$ \\
\hline \multirow[t]{2}{*}{$\begin{array}{l}\text { Throes episodes } \\
\text { per day }\end{array}$} & $\begin{array}{l}\text { Before } \\
\text { treatment }\end{array}$ & $5,30 \pm 0,80$ & $5,67 \pm 0,97$ \\
\hline & $\begin{array}{l}\text { After } \\
\text { treatment }\end{array}$ & $0,43 \pm 0,09 *$ & $0,50 \pm 0,12 *$ \\
\hline \multirow{2}{*}{$\begin{array}{l}\text { Daily } \\
\text { nitroglycerin } \\
\text { maintenance } \\
\text { (pills) }\end{array}$} & $\begin{array}{l}\text { Before } \\
\text { treatment }\end{array}$ & $5,43 \pm 1,21$ & $5,00 \pm 1,36$ \\
\hline & $\begin{array}{l}\text { After } \\
\text { treatment }\end{array}$ & $0,01 \pm 0,001 *$ & $1,17 \pm 0,98$ \\
\hline \multirow[t]{2}{*}{$\mathrm{HR}$, beats/min } & $\begin{array}{l}\text { Before } \\
\text { treatment }\end{array}$ & $71,5 \pm 4,7$ & $69,6 \pm 3,3$ \\
\hline & $\begin{array}{l}\text { After } \\
\text { treatment }\end{array}$ & $62,0 \pm 1,8 *$ & $62,6 \pm 1,3 *$ \\
\hline \multirow[t]{2}{*}{$\mathrm{SBP}, \mathrm{mmHg}$} & $\begin{array}{l}\text { Before } \\
\text { treatment }\end{array}$ & $143,3 \pm 5,2$ & $141,2 \pm 5,7$ \\
\hline & $\begin{array}{l}\text { After } \\
\text { treatment }\end{array}$ & $130,8 \pm 3,5 *$ & $125,1 \pm 3,9 *$ \\
\hline \multirow[t]{2}{*}{$\mathrm{DBP}, \mathrm{mmHg}$} & $\begin{array}{l}\text { Before } \\
\text { treatment }\end{array}$ & $93,4 \pm 4,8$ & $92,6 \pm 3,8$ \\
\hline & $\begin{array}{l}\text { After } \\
\text { treatment }\end{array}$ & $80,9 \pm 3,4 *$ & $78,1 \pm 2,7 *$ \\
\hline
\end{tabular}

SBP, systolic blood pressure; DBP, diastolic blood pressure.

* - difference with "before treatment" parameter is statistically valid $(\mathrm{p}<0.05)$.

\section{Discussion}

The received results demonstrate that THz-therapy-NO has a positive effect on smoking and in non-smoking patients with angina. There had not been found principle differences in a rapid relief of angina symptoms. There had not been found also a difference in an effect on systolic and diastolic arterial pressure, and on a HR. The validity of these results is confirmed by the fact that a drug therapy in the both groups did not differ.

These results were slightly surprisingly fond out; as it is known that smoking stimulates spastic reactions, increase of thrombogenic blood potency, reduce of natural protective mechanisms. It's no coincidence that smoking is one of risk factors of an IHD developing. It would be a norm to suppose that all these change are not connected with change in NO cycle activity and, as a result a sensitivity to the THz-therapy-NO in smoking and in nonsmoking patients should have been different. Nevertheless we had not got statistically valid data that confirm the given hypothesis. A degree of angina episodes decrease and a positive change in central hemodynamics in the examined patients were the same.

These data cannot be explained by sex difference in the groups (all of the smokers are men, the non-smokers are mostly women) as in earlier studies there had been displayed that antianginal and pulse slowing effects of $\mathrm{THz}$ waves do not depend on a sex of the patients with angina, and the peculiarities of antihypertensive effect are connected only with systolic arterial pressure (AP decreases in men more intensive than in women at the $\mathrm{THz}$ therapy-NO exposure).

Today there is much experimental information that proves a realization of $\mathrm{THz}$-therapy-NO effects through the modulation of NO cycle activity [9]. Together with this our results let suppose that $\mathrm{THz}$ waves effect on NO cycle activity is, probably, not the 
only mechanism of the THz-therapy-NO exposure on a human organism. It is possible that $\mathrm{THz}$-therapy effects are realized also through the same strong stress-limiting mechanisms of a general regulation as a nitrogen oxide system is realized through heat shock proteins.

At the same time an interpretation of the received information about independence of $\mathrm{THz}$-therapy-NO effects on a smoking factor can be explained as follows. The $\mathrm{THz}$ waves exposure touches upon so many regulating systems that their overall reaction is much stronger than hemostasis change under extrinsic factor influence (smoking, for instance).

Together with this one of the facts described in this study calls for a special discussion. In the group of non-smokers angina episodes were accompanied by a statistically valid decrease of daily nitroglycerin maintenance, which is rather logical. In the group of smokers, at the decrease of angina episodes after the treatment, there was fixed a tendency to reduce of daily nitroglycerin maintenance, but not a statistically valid dynamics of this parameter. Analogical situation can appear at a decrease of those angina episodes which do not request nitroglycerin taking mild attacks. So their total number decreases, and the amount of nitroglycerin is not changed significantly. We think that the revealed results should be confirmed by more representative samplings, and if they will confirm, this is the validation of a difference between smokers and non-smokers patients with angina and their sensitivity to $\mathrm{THz}$ waves. At the present moment this fact does not let affirm that there is the difference, because a statistically valid dynamics of other parameters proves a contrary.

The received data of antianginal, pulse slowing and antihypertensive effects of THz-therapy-NO in smoking and nonsmoking patients with angina have the following practical value: at the present moment an individual parameters of irradiation is not necessary in the treatment of the patients with angina, depending on a smoking factor. In the case of a treatment futility it is necessary to analyze other reasons, as a smoking resistant angina does not relate directly to refractoriness to $\mathrm{THz}$ waves.

\section{Conclusion}

1. Antianginal THz-therapy-NO effect is the same in smoking and non-smoking patients with angina.

2. THz waves effect on systolic and diastolic AP in smoking and non-smoking patients with angina does not differ.

3. Smoking does not influence the evidence of a pulse slowing $\mathrm{EMI}$ of THz-NO effect in the patients with angina.

4. In smoking patients mild episodes of angina decrease, without nitroglycerin, in non-smoking patients decreased a total frequency of all angina episodes. These data need to be confirmed.

5. It is necessary to continue the study after increase of the patients' samplings.

Conflict of interest: none declared.

\section{Reference}

1. Parshina SS, Kirichuk VF, Golovacheva TP. First clinical experience with electromagnetic radiation at terahertz frequencies of molecular spectrum of nitrogen oxide. Biomedical Radioelectronics 2004; (11): 46-54. [Article in Russian]
2. Parshina SS, Kirichuk VF, Golovacheva TV, Afanasyeva TN, Tupikin VD, Krenitsky AP, Mayborodin AV, Lopatina NA. Electro-magnetic radiation of terahertz range, NO molecular specter frequencies, and coagulation hemostasis in patients with various angina forms. Cardiovascular Therapy and Prevention 2006; (4): 70-74. [Article in Russian]

3. Parshina SS. Clinical features of the use of THz-therapy-NO in the patients with angina. Biomedical Radioelectronics 2006; (1-2): 4-11. [Article in Russian]

4. Parshina SS, Afanasieva TN, Golovacheva TV, et.al. Features of the use of THz-therapy-NO in the patients with angina and a concomitant hypertention. In: Millimeter waves in medicine and biology, Edited volume of the Russian intermational conference, Moscow, 2007: 5255. [Text in Russian]

5. Parshina SS, Golovacheva TV, Afanasjeva TN, Glukchova NA, Potapova MV, Grizenger VR, et.al. Particularities of the hemodynamic effects of the terahertz therapy in patients with angina pectoris of both sexes. Biomedical Radioelectronics 2011; (8): 58-63. [Article in Russian]

6. Vanin AF. The Nobel Prize for physiology and medicine, 1998. URL: http://badis.narod.ru/home/histor/his_nobel.html

7. Menshikova EB, Zenkov NK, Reutov VP. Nitric oxide and NO-synthases in mammals in different functional states. Biochemistry (Mosc) 2000; 65(4): 409-426. (PMID: 10810177)

8. Severina IS. Role of soluble guanylate cyclase in the molecular mechanism underlying the physiological effects of nitric oxide. Biochemistry (Mosc) 1998; 63(7): 794-801. (PMID: 9721331)

9. Kirichuck VF, Ivanov AN, Kulapina EG, Krenickiy AP, Mayborodin AV. Effect of Terahertz Electromagnetic Irradiation at Nitric Oxide Frequencies on Concentration of Nitrites in Blood Serum of Albino Rats under Conditions of Immobilization Stress. Bull Exp Biol Med 2011; 149(2): 174-176. (PMID: 21113484) (doi: 10.1007/s10517-010-0900-9)

\section{Authors:}

Svetlana S. Parshina - MD, D.Sc., Professor, Department of Therapy, Faculty training and retraining of specialits, Saratov State Medical University n.a. V.I. Razumovsky, Saratov, Russia. 